\title{
Absence of relationship between tuberculin reactivity and atopy in BCG vaccinated young adults
}

\author{
E Omenaas, H F Jentoft, W M Vollmer, A S Buist, A Gulsvik
}

\section{Department of Thoracic Medicine, University of Bergen, Norway \\ E Omenaas \\ H F Jentoft \\ A Gulsvik}

Kaiser Permanente Center for Health

Research

W M Vollmer

Oregon Health Sciences University, Portland, Oregon, USA

A S Buist

Correspondence to: Dr E Omenaas, Department of Thoracic Medicine, Haukeland University Hospital, N-5021 Bergen, Norway

email:

ernst.omenaas@meda.uib.no

Received 28 July 1999 Returned to authors 14 October 1999

Revised version received 26 January 2000

Accepted for publication

16 February 2000

\begin{abstract}
Background-An inverse association between tuberculin responses and atopy has been observed in Japanese children, indicating that BCG immunisation, subclinical exposure to Mycobacterium tuberculosis without clinical disease, or host characteristics may influence the $T$ helper (Th) lymphocyte balance with decreased atopy as a result. This study was undertaken to determine whether tuberculin reactivity is inversely related to atopy in young adults vaccinated with BCG at the age of 14 .

Methods-Men and women aged 20-44 years were tested using the adrenalinePirquet test with Norwegian produced synthetic medium tuberculin $(n=891)$. In addition, their serum total and specific IgE antibodies against mite, cat, timothy grass, mould and birch were measured.

Results-Of the 574 subjects with complete examinations, $64 \%$ had a positive adrenaline-Pirquet tuberculin test $(\geqslant 4 \mathrm{~mm}$ ) and $27 \%$ exhibited IgE antibodies $(\geqslant 0.35 \mathrm{kU} / \mathrm{l})$ to one or more of the five specific allergens. The geometric mean of total serum IgE in the population was $30.2 \mathrm{kU} / 1$. Tuberculin reactivity and $\log$ IgE were not correlated $(r=0.043, p=$ $0.30)$. The mean tuberculin reactivity was $4.6 \mathrm{~mm}, 4.9 \mathrm{~mm}$, and $5.0 \mathrm{~mm}$ in the lower, middle and upper tertile of IgE distribution (<14 kU/1, 14-61 kU/1, >61 kU/1). The prevalence of atopy, as assessed by either the presence of any of the five specific IgE antibodies or by each specific IgE antibody separately, did not differ between subjects with a positive and those with a negative tuberculin test. These results persisted after adjustment for age, sex, and smoking status in multivariate logistic regression analyses.

Conclusions-In this young adult population, BCG vaccinated at the age of 14 , no significant relationship between a positive tuberculin reaction and atopy was observed. If a true relationship had been found, our study suggests that it may be limited to populations immunised in early childhood when a substantial modulation of the immune system can occur.

(Thorax 2000;55:454-458)
\end{abstract}

Keywords: atopy; asthma; tuberculosis; immunisation, BCG vaccination
T helper (Th) lymphocytes have a central regulatory role in allergic inflammation and can be subdivided according to their production of cytokines. ${ }^{1}$ When stimulated by some respiratory infections or immunisation with attenuated bovine Mycobacterium tuberculosis vaccine (BCG), Th1 can secrete interferon (IFN) $-\gamma$ and interleukin (IL)-2 which can inhibit B lymphocyte production of $\mathrm{IgE} .^{2} \mathrm{By}$ contrast, Th2 cells, when stimulated by allergens such as house dust mite, grass and pollen, release IL-4 which promotes IgE production by the B lymphocytes. Th2 responses dominate in atopic individuals and may infer subsequent expression of disease including asthma. ${ }^{3}$ Furthermore, the absence of infections in childhood might, according to the microbial stimulation hypothesis, release $\mathrm{Th} 2$ immune mechanisms and thus promote allergic asthma. $^{4}$

Shirakawa et al reported an inverse association between tuberculin responses and atopic disorders in Japanese children ${ }^{5}$ which suggested that BCG immunisation or subclinical exposure to $M$ tuberculosis from birth up to the age of 12 years may influence the Th lymphocyte balance with decreased atopy as a result. An alternative explanation is that host characteristics such as the genetically determined balance of Th 1 and Th2 responsiveness may generate a non-causal inverse relationship between tuberculin response (Th1) and atopy (Th2). Swedish investigators, however, have not observed a significant relationship between BCG vaccination during the first year of life and development of atopy in children, assessed either by a questionnaire ${ }^{6}$ or by skin prick tests and measurement of serum specific $\operatorname{IgE}$ antibodies. $^{7}$ Although the evidence for an association between BCG vaccination and atopy is inconsistent, one could question whether such a relationship may be extended to immunisation in adolescence or whether it is limited to vaccinations given early in infancy. The plasticity of the immune system and the gains of immune deviation may at that time be greater than later in life. ${ }^{8}$ We have used tuberculin reactivity as an indicator of the effect of the previous BCG vaccination, which is the only one except assessing the presence of a scar. Previous observation in our area showed that about $80 \%$ of the subjects were positive tuberculin reactors three months after BCG vaccination, while the figures were reduced to $70 \%$ and $60 \%$, respectively, one and 10 years after BCG vaccination. ${ }^{9}$ In Norway mandatory BCG vaccination is given at the age of 14 and 
therefore all children are exposed to mycobacterial antigen at this time. We investigated whether a stronger tuberculin reactivity during adult life was related to lower levels of total and specific serum IgE when examined cross sectionally in young adults. A lack of association would argue against the "host characteristic" interpretation of the Japanese findings.

\section{Methods}

STUDY POPULATION

A random sample of 1200 men and women aged 20-44 years living in Bergen, Norway was invited to participate in the Norwegian part of the European Community Respiratory Health Survey, ${ }^{10}$ and 903 subjects $(75.3 \%)$ attended the study from September 1992 to June 1993. Twelve subjects were excluded from skin testing due to eczema. Of the 891 subjects who underwent tuberculin and allergy testing, including measurements of serum total and specific IgE antibodies, $574(64 \%)$ returned after 2-7 days (42-171 hours) to have their tuberculin reactions read. Of these, nine were tuberculin converters and had never received BCG vaccination, seven had no information on their BCG status, while 558 subjects had been vaccinated with BCG at the age of 14 .

TUBERCULIN AND ALLERGY TESTING

Each subject was tested using the Norwegian reference method of adrenaline-Pirquet in duplicate on the volar side of the forearm. The adrenaline-Pirquet test is a modification of von Pirquet's skin scarification method ${ }^{11}$ that uses Norwegian produced synthetic tuberculin (SMT 14) and adrenaline. ${ }^{12} 13$ The repeatability of the test is comparable to that observed for the Mantoux test. ${ }^{14}$ The adrenaline-Pirquet reactions are recommended to be read at 48-72 hours, but the test appeared to be independent of time of reading within four days. ${ }^{14}$ The adrenaline-Pirquet tuberculin reaction should be read as the highest value at $90^{\circ}$ to the scratch line and a diameter of $\geqslant 4 \mathrm{~mm}$ is taken as a positive result. ${ }^{15}$ The larger of the duplicate adrenaline-Pirquet reactions is used for screening ${ }^{16}$ as well as for the analyses in the present study. Every subject was offered a miniature chest radiograph and no subjects had findings indicating active or inactive tuberculous disease.

For measurements of serum $\mathrm{IgE}, 10 \mathrm{ml}$ of venous blood was taken from each subject, coagulated at room temperature, centrifuged, stored at $-20^{\circ} \mathrm{C}$, packed, and sent on dry ice to Pharmacia Diagnostics AB (Uppsala, Sweden). Serum specific and total IgE levels were measured using the Pharmacia CAP system. ${ }^{17}$ The working range for the total $\mathrm{IgE}$ assay was $2-2000 \mathrm{kU} / 1$. All subjects had detectable IgE, and one subject had a value of more than $2000 \mathrm{kU} / 1$ (assigned as $2050 \mathrm{kU} / \mathrm{l}$ ). All assays for specific IgE were judged to be positive if they had more than $0.35 \mathrm{kU} / 1$ of the specific allergen. Specific IgE levels were measured against house dust mite (Dermatophagoides pteronyssinus), timothy grass, cat, mould (Cladosporium herbarum), and a local allergen (birch). Tuberculin and allergy testing as well as the reading of all skin tests was performed by the same experienced public health nurse who was blinded to the serological outcome of serum IgE results at the time of the tuberculin reading.

\section{ENVIRONMENTAL EXPOSURES}

Participants were categorised as non-smokers, ex-smokers, or smokers according to the ECRHS questionnaire. ${ }^{10}$ Smokers were those who had smoked at least one cigarette a day or one cigar a week for as much as one year or who had smoked at least 400 cigarettes or $360 \mathrm{~g}$ tobacco during their lifetime; ex-smokers were those who had stopped smoking more than one month previously; and non-smokers had never smoked, using the above definitions. Occupational exposure was assessed by asking: "Have you ever worked in a job which exposed you to vapours, gas, dust or fumes?" The answers were given as yes $(n=261)$ or no $(n=313)$.

DATA MANAGEMENT AND ANALYSIS

Serum total IgE values were log transformed in order to obtain a Gaussian distribution. To investigate bivariate relationships between tuberculin positivity and specific IgE antibodies we used a corrected $\chi^{2}$ test. The power was generally too low $(55 \%)$ to detect an odds ratio of 1.5 but was adequate (96\%) for an odds ratio of 2.0 when using the any of the five specific IgE antibodies as variables. For the individual allergens the power was somewhat lower. Standard methods for contingency tables such as $\chi^{2}$ tests and logistic regression analysis were used to compare proportions. One way analysis of variance and general linear models were used to compare continuous outcomes. In the multivariate analyses we used the variable "any of the five specific antibodies" rather than the individual specific IgE antibodies variable to obtain more statistical power.

When examining positive predictors for the presence of a positive tuberculin reaction, a multiple logistic regression model was applied including sex, age, smoking status, occupational exposure to dust or gas, level of total IgE antibodies, any of the five specific IgE antibodies, and first order interactions between these variables. Interactions were checked for statistical significance in a backward stepwise manner. From previous knowledge it was decided to include sex, smoking status, and occupational exposure in the model regardless of their statistical significance in the final analysis. All the statistical analyses were performed with the BMDP package. ${ }^{18}$

\section{Results}

PARTICIPATION RATES AND STUDY POPULATION The characteristics of the study population are presented in table 1 . Subjects invited to the clinical examination who did not attend even after two reminders were defined as nonattenders. Non-attenders were slightly younger than attenders and were more often men. Of those with complete examinations, 95\% had been BCG vaccinated while $2 \%$ were tuberculin converters when examined before the scheduled BCG vaccination at the age of 14 . 
Table 1 Characteristics of the study population by response status in 20-44 year old Norwegian men and women $*(n=1200)$

\begin{tabular}{|c|c|c|c|c|}
\hline & Non-attenders $(n=297)$ & $\begin{array}{l}\text { Attenders allergy and tuberculin tested } \\
\text { but not read }(n=329)\end{array}$ & $\begin{array}{l}\text { Attenders allergy and tuberculin tested } \\
\text { and readt }(n=574)\end{array}$ & $p$ value $\neq$ \\
\hline Men, n (\%) & $176(59)$ & $172(52)$ & $288(50)$ & $<0.01$ \\
\hline Mean (SD) age (years) & $32(7)$ & $33(6)$ & $34(7)$ & $<0.01$ \\
\hline $\begin{array}{l}\text { Spontaneous tuberculin } \\
\text { converters prior to BCG } \\
\text { vaccination, } \mathrm{n}(\%)\end{array}$ & - & $8(3)$ & $9(2)$ & 0.28 \\
\hline BCG vaccinated, n (\%) & - & $319(98)$ & $558(95)$ & 0.13 \\
\hline
\end{tabular}

${ }^{\star}$ Randomly drawn from the general population of Bergen, Norway in 1991.

†Two sided $\mathrm{p}$ values based on corrected $\chi^{2}$ tests for proportions and on one way ANOVA for age.

$\ddagger$ Nineteen subjects did not have documented information on their BCG vaccination status and were classified as unknown.

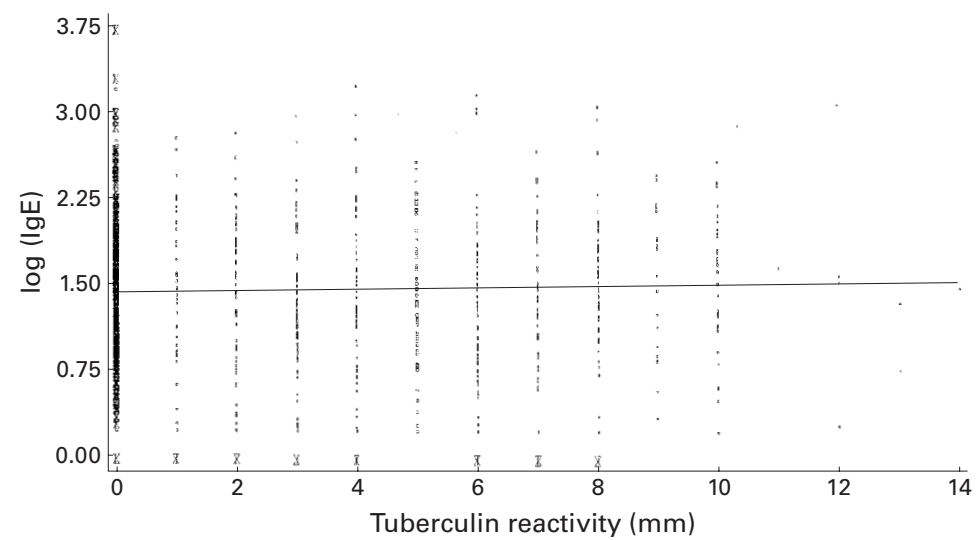

Figure 1 Tuberculin reactivity by total serum IgE in young Norwegian adults $(n=574)$.

All subsequent analyses were restricted to the 574 participants for whom complete tuberculin reactivity and IgE data were available.

DISTRIBUTION OF TUBERCULIN REACTIVITY

The distribution of tuberculin reactivity in these young adults is shown in fig 1 . A positive test, defined as a reaction of $\geqslant 4 \mathrm{~mm}$ diameter, was obtained in 357 subjects $(64 \%)$. The mean (SD) tuberculin reaction for all subjects was 4.8 (3.0) $\mathrm{mm}$. A significant increase in tuberculin reactivity was observed with increasing age (regression coefficient 0.037, p<0.01), ranging from $3.1 \mathrm{~mm}$ in those aged $20-24$ years to $4.9 \mathrm{~mm}$ in those aged $40-44$ years. Tuberculin reactivity was also higher in men than in women $(5.2$ versus $4.4 \mathrm{~mm}, \mathrm{p}<0.01$ ) and in smokers than in non-smokers (5.1 versus $4.3 \mathrm{~mm}, \mathrm{p}<0.01)$.

DISTRIBUTION OF IGE

The geometric mean total serum IgE concentration was $30.2 \mathrm{kU} / 1$ with higher levels in smokers than in non-smokers (35.7 versus $27.1 \mathrm{kU} / 1, \mathrm{p}<0.01$ ) but no significant variation with age or sex. One or more of the five specific IgE antibodies was observed in $27 \%$ of those examined (house dust mite $14 \%$, cat $8 \%$, timo- thy grass $16 \%$, birch $10 \%$, and moulds $2 \%$ ). The probability of having a positive response to any of the five allergens or having each of the specific IgE antibodies separately did not vary significantly $(\mathrm{p}<0.05)$ with sex or smoking category. The prevalence of one or more of the specific IgE antibodies decreased significantly with increasing age $(\mathrm{p}<0.01)$, ranging from $31 \%$ in those aged $20-24$ years to $18 \%$ in those aged $40-44$ years.

UNIVARIATE RELATIONSHIP BETWEEN TUBERCULIN REACTIVITY AND IGE

Tuberculin reactivity and $\log \operatorname{IgE}$ values were uncorrelated in this young population $(r=$ $0.043, p=0.30$; fig 1$)$. The mean tuberculin reactivity in the lower, middle, and upper tertile of $\mathrm{IgE}$ distribution $(<14 \mathrm{kU} / \mathrm{l}, 14-$ $61 \mathrm{kU} / 1,>61 \mathrm{kU} / \mathrm{l})$ was $4.6 \mathrm{~mm}, 4.9 \mathrm{~mm}$, and $5.0 \mathrm{~mm}$, respectively. Although not significantly different $(p=0.19$ in test for equality of slopes), increasing tuberculin reactivity in nonsmokers tended to be associated with slightly decreasing $\log \operatorname{IgE}$ levels while in smokers and ex-smokers the association was reversed.

The prevalence of a positive IgE response to any of the five specific IgE allergens did not differ between subjects with a positive and a negative tuberculin test (table 2). Furthermore, no significant differences with age, sex, or smoking habit were observed in having any of the five specific IgE antibodies $(p<0.05)$. The pattern appeared to be similar for the individual specific allergens.

\section{MULTIVARIATE RELATIONSHIP BETWEEN}

TUBERCULIN REACTIVITY AND IGE

In the multiple logistic regression analyses none of the interactions was statistically significant. The odds ratio for positive tuberculin reactivity was not related to the level of total serum IgE antibodies nor to the presence of any of the five specific $\operatorname{IgE}$ antibodies measured (table 3). However, the odds ratio for being tuberculin reactive was significantly higher in men than in women, in older than in younger

Table 2 Distribution of specific IgE antibodies ( $>0.35 \mathrm{kU} / \mathrm{l}$ ) by tuberculin reactivity status assessed with the adrenaline-Pirquet method in young Norwegian adults

\begin{tabular}{llll}
\hline & $\begin{array}{l}\text { Tuberculin negative }(<4 \mathrm{~mm}) \\
(n=207)\end{array}$ & $\begin{array}{l}\text { Tuberculin positive }(\geqslant 4 \mathrm{~mm}) \\
(n=367)\end{array}$ & $p$ value* \\
\hline House dust mite & $25(12.1 \%)$ & $57(15.5 \%)$ & 0.27 \\
Cat & $19(9.2 \%)$ & $27(7.9 \%)$ & 0.57 \\
Timothy grass & $31(15.0 \%)$ & $63(17.1 \%)$ & 0.52 \\
Mould & $7(3.4 \%)$ & $5(1.4 \%)$ & 0.10 \\
Birch & $19(9.2 \%)$ & $38(10.3 \%)$ & 0.67 \\
Any of these & $56(27.2 \%)$ & $108(29.3 \%)$ & 0.58 \\
\hline
\end{tabular}

*Two sided $\mathrm{p}$ values based on corrected $\chi^{2}$ tests.

House dust mite $=$ Dermatophagoides pteronyssinus $;$ mould $=$ Cladosporium herbarum . 
Table 3 Adjusted odds ratios (OR) and 95\% confidence intervals (CI) for having a positive adrenaline-Pirquet tuberculin test $(\geqslant 4 \mathrm{~mm})$ in young Norwegian adults based on multiple logistic regression analysis

\begin{tabular}{|c|c|c|c|}
\hline & No. & $O R$ & $95 \% C I$ \\
\hline \multicolumn{4}{|l|}{ Total serum IgE tertiles } \\
\hline Lower $(<14 \mathrm{kU} / \mathrm{l})$ & 189 & 1 & \\
\hline Middle $(14-61 \mathrm{kU} / \mathrm{l})$ & 192 & 1.0 & 0.7 to 1.6 \\
\hline Upper $(>61 \mathrm{kU} / \mathrm{l})$ & 193 & 1.1 & 0.7 to 1.8 \\
\hline \multicolumn{4}{|c|}{ Any of the specific IgE antibodies $(\geqslant 0.35 \mathrm{kU} / \mathrm{l})$} \\
\hline No & 410 & 1 & \\
\hline Yes & 164 & 1.3 & 0.8 to 1.9 \\
\hline \multicolumn{4}{|l|}{ Sex } \\
\hline Women & 283 & 1 & \\
\hline Men & 291 & 1.3 & 0.9 to 2.0 \\
\hline \multicolumn{4}{|l|}{ Age (years) } \\
\hline $20-29$ & 228 & 1 & \\
\hline $30-39$ & 237 & 2.4 & 1.7 to 3.6 \\
\hline $40-44$ & 109 & 4.6 & 2.6 to 7.7 \\
\hline \multicolumn{4}{|l|}{ Smoking } \\
\hline Non-smoker & 233 & 1 & \\
\hline Ex-smoker & 88 & 1.2 & 0.7 to 2.1 \\
\hline Smoker & 253 & 1.5 & 1.1 to 2.3 \\
\hline \multicolumn{4}{|c|}{ Occupational dust or gas exposure } \\
\hline No & 313 & 1 & \\
\hline Yes & 261 & 1.2 & 0.8 to 1.8 \\
\hline
\end{tabular}

All variables in the table were included simultaneously in the logistic regression model.

subjects, and in smokers than in non-smokers (table 3). An analysis of the variables shown in table 3 stratified by smoking status showed an effect of the same magnitude across smoking categories.

\section{Discussion}

We found that a positive tuberculin test was significantly related to age and smoking habits but not to markers of atopy (total and specific IgE antibodies) in this young adult population from Bergen, Norway, most of whom had received BCG vaccination at the age of 14 years. These results were consistent in both the univariate and multivariate analyses.

The study population, drawn randomly from the general population, consisted of young men and women living in Bergen, Norway. The participation rate in the study was $75 \%$. However, less than $50 \%$ of those invited returned to have their tuberculin reactivity test read after 2-3 days. As with other population studies performed in the same area, ${ }^{19}$ those who returned were somewhat older and included a lower proportion of men. The main purpose of this study was the assessment of respiratory health in general, ${ }^{10}$ and the selection was not on the basis of BCG vaccination, tuberculin status, or disease. We therefore believe that the exclusion of attenders who were allergy and tuberculin tested but not read should not have biased our results to a substantial degree. The difference in the mean age of those who did and did not return to have their tests read was only one year and the percentage of tuberculin converters prior to BCG vaccination was at the same level.

BCG immunisation status was assessed using the adrenaline-Pirquet test with synthetic medium tuberculin. This test has recently been shown to be comparable with the Mantoux test in terms of reproducibility ${ }^{14}$ and the proportion of tuberculin reactors in a population. ${ }^{20}$

Until 1995 BCG vaccination was mandatory in Norway at the age of 14 years, except for those who had a positive synthetic medium tuberculin test or in whom the test was contraindicated. The study population was born between 1947 and 1971 when the BCG coverage in this population was approximately $95 \%$. The incidence of tuberculous disease in the community in this age group has been less than one per $100000 .{ }^{21}$ Consistent with this, we did not observe any subjects in the study population with tuberculous disease.

Our markers of atopy (serum total and specific IgE levels) are widely used and well recognised markers and have been applied in large epidemiological studies. The total serum IgE levels, as well as specific IgE levels, were lower than those observed in the UK, North America, Australia and New Zealand. ${ }^{17} \mathrm{~A}$ significant relationship between total $\mathrm{IgE}$ and specific $\operatorname{IgE}$ as markers of atopy has been observed in a previous population study from Norway, ${ }^{19}$ indicating that these IgE measurements are highly related to atopy in this northern environment. In other areas of the world IgE reactivity may be driven by other environmental exposures, as indicated by the ECRHS survey where no relationship between total and specific IgE was observed. ${ }^{17}$ We therefore believe that total and specific serum IgE measurements are useful markers of atopy in the present study.

Shirakawa et a $\bar{P}$ observed an inverse association in Japanese children between tuberculin responses and atopic disorders, indicating that immunisation, subclinical exposure to $M$ tuberculosis, or host characteristics from birth to the age of 12 years may influence the Th lymphocyte balance with decreased atopy in children as a result. In the same study subjects converting to a positive tuberculin test at the age of 12 appeared to have less atopy and symptomatic asthma than those converting at the age of six. This might suggest that immunisation may have a role in modulation of the immune system in older children as well. Furthermore, in a retrospective analysis, immunisation with whole cell pertussis vaccine was found to be a predictor of allergic asthma, hay fever, and eczema. ${ }^{22}$ However, other investigators have not observed a significant relationship between BCG vaccination and development of atopy in children, ${ }^{67}$ One might therefore speculate whether BCG vaccination, primary 
tuberculosis infection early in childhood, or sensitisation to environmental mycobacteria was responsible for tuberculin responsiveness in the Japanese study. Approximately $1-2 \%$ of Norwegian school children have a positive tuberculin reaction before the scheduled BCG vaccination at the age of 14 , mostly as a result of infection with environmental mycobacteria. ${ }^{21}$ Later in life a positive tuberculin reaction may be observed as a result of exposure and infection by environmental mycobacteria. However, it is unlikely that these numbers would be so high in young healthy Norwegian adults that it would affect our observations. In general, differences in host characteristics, indoor and outdoor environmental exposures, family size, and immunisation programmes/assessment may be of importance when explaining differences between Scandinavian and other studies.

Since BCG vaccination of the population is performed in only a few countries, this Norwegian population with its high coverage of BCG vaccination could be used to assess the relationship between tuberculin reactivity and atopy using well recognised markers of atopy. We did not observe significant relationships between a positive tuberculin test and markers of atopy in young men and women when immunisation was performed at the age of 14 . This might suggest that host characteristics such as the Th1/Th2 balance do not explain the relationship between tuberculin reactivity and atopy observed in the younger Japanese population. ${ }^{5}$ If a true relationship exists between tuberculin reactivity and atopy, our study suggests that this relationship may be limited to populations immunised in early childhood when a substantial modulation of the immune system can occur.

The authors acknowledge public health nurse Mrs Berit DragThe authors acknowledge public health nurse Mrs Berit Drageset who performed the tuberculin testing and reading and
nurse Mrs Bjørg Meidell who did the interviews and data regisnurse Mrs Bjørg Meidell who did the interviews and data regis-
tration. The authors are grateful for their accuracy and persisttration. The authors are grateful for their accuracy and persist-
ence. We also thank Geir Egil Eide for statistical advice. The study was supported by the Norwegian Research Fund for Asthma and Allergy and the Norwegian Research Council.

1 Romagnani S. Induction of Th1 and Th2 responses: a key role for the "natural" immune response. Immunol Today role for the "natur

2 Martinati L, Boner A. The inverse relationship between tuberculin responses and atopic disorder. Allergy 1997;52: 1036-7.

3 Prescott S, Macaubas C, Smallacombe T, et al. Development of allergen-specific T-cell memory in atopic and normal children. Lancet 1999;353:196-200.

4 Cookson O, Moffatt M. Asthma: an epidemic in the absence of infection? Science 1997;275:41-2.

5 Shirakawa T, Enomoto T, Shimazu S, et al. The inverse association between tuberculin responses and atopic disorder. Science 1997;275:77-9.

6 Strannegård I-L, Larsson L-O, Wennergren G, et al. Prevalence of allergy in children in relation to prior BCG vaccination and infection with atypical mycobacteria. Allergy 1998;53:249-54.

7 Alm J, Lilja G, Pershagen G, et al. Early BCG vaccination and development of atopy. Lancet 1997;350:400-3.

8 Silverman M. BCG vaccination and atopy: unfinished busiSilverman M. BCG vaccination
ness? Lancet 1997;350:380-1.

9 Eilertsen E. Tuberculosis infection in childhood and adolescense. Acta Tub Pneum Scand 1964; 34(Suppl LX):84-7.

10 European Community Respiratory Health Survey. Variations in the prevalence of respiratory symptoms, selfreported asthma attacks, and use of asthma medication in the European Community Respiratory Health Survey (ECRHS). Eur Respir F 1996;9:687-895.

11 von Pirquet C. Demonstration zur Tuberkulindiagnose durch Hautimpfung. Berl Klin Wschr 1907;48:699.

12 Bjørlo R, Saxegaard F, Næss B. Preparation of synthetic medium tuberculin (SMT14). Oslo, Norway: National Veterinary Institute, 1985.

13 Hansen $\mathrm{O}$. The value of the addition of adrenaline to tuberculin used in the von Pirquet test. Acta Tuberc Scand 1937; 6:130.

14 Jentoft H, Omenaas E, Eide G, et al. Agreement between dual adrenaline-Pirquet tests and time dependence of reading. Int f Tuberc Lung Dis 1999;4:326-9.

15 Waaler H, Galtung O, Mordal K. The risk of tuberculosis infection in Norway. Tuberculosis surveillance. Bull Int Unfection Tuberc 1975;1:5-61.

16 Bjartveit K, Heldal E, Sandven P, et al. Control of tuberculosis. Manual for the community health service (in Norwegian). 3rd ed. Oslo, Norway, 1996.

17 European Community Respiratory Health Survey. The distribution of total and specific serum IgE in the European Community Respiratory Health Survey. $f$ Allergy Clin Immunol 1997;99:314-22.

18 Dixon J. BMDP statistical software manual. Berkeley, CA: University of California Press, 1990.

19 Omenaas E, Bakke P, Elsayed S, et al. Total and specific serum IgE levels in adults: relationship to sex, age and environmental factors. Clin Exp Allergy 1994;24:530-9.

20 Jentoft HF, Omenaas E, Eide GE, et al. Comparing reactivity to three different tuberculin tests. Eur Respir $f$ ity to three different tube

21 Bjerkedal T. Mycobacterial infections in Norway: a preliminary note on determining their identity and frequency. $A m$ 7 Epidemiol 1967;85:157-73.

22 Farooqi I, Hopkin J. Early childhood infection and atopic disorder. Thorax 1998;53:927-32. 